\title{
Privacy Policy in E Government Websites: A Case Study of Saudi Arabia
}

\author{
Sami M. Alhomod \\ E learning and distance learning deanship, King Saud University \\ PO Box 231201, Riyadh 11321, Kingdom Of Saudi Arabia \\ E-mail: Alhomod@Ksu.Edu.Sa \\ Mohd Mudasir Shafi \\ E learning and distance learning deanship, King Saud University \\ Riyadh 11321, Kingdom Of Saudi Arabia \\ E-mail: Mmudasir@Ksu.Edu.Sa
}

Received: December 20, 2011 Accepted: January 4, $2012 \quad$ Published: March 1, 2012

doi:10.5539/cis.v5n2p88 URL: http://dx.doi.org/10.5539/cis.v5n2p88

\begin{abstract}
Information privacy has been one of the areas of extended discussion over a past decade. There has been a lot of discussion about the information privacy online. Presence of a privacy page in a website is one way of ensuring privacy in a website. This paper is concerned with the presence of privacy policy in e government websites of Saudi Arabia. During the course of this study we looked for the presence of privacy policy in E government websites of Saudi Arabia. This paper presents the result of the study, and the aim is to draw attention of the governing bodies and Administrators towards the privacy policy implementation in their websites.
\end{abstract}

Keywords: Websites, Privacy policy, Data privacy, Web privacy, Universities, Educational collages, Data privacy laws, Internet laws, Saudi Arabia

\section{Introduction}

The advancement in computer and communication technology has changed the way information is processed over the internet. There has been a lot of discussion about the privacy of the information online. Privacy over the internet is one of the most prominent issues concerning the online world today. A lot of attention is paid to online information over the internet and every website to implement some kind of privacy in their website. The first and most important step of ensuring privacy in the virtual environment is the presence of privacy policy in the website. A privacy policy is a legal document that defines how the website gathers information from the user and how it uses this information. It also provides information about the access to this information. Most websites provide a link to the privacy page of the website. There are no standards and requirements for writing a privacy policy and hence there is no standard definition of the privacy policy.

The contents of the privacy policy depend upon the requirements of the organisation. The contents of the privacy policy depend upon the law applicable in that region and may also need to address the laws of multiple countries and their jurisdiction.

Users over the internet are very concerned about the information that they disclose over the internet. Most users need some kind of assurance before they disclose information to a website. The presence of privacy policy is one approach, which boosts user confidence over the website and also reduces the chance of receiving false information from the user.

Keeping the importance of ensuring privacy in the mind, we conducted a study on the Presence of privacy policy in E government websites of Saudi Arabia. The e government websites represent the government of the particular place over the internet. So, ensuring privacy of the e government website is extremely important. The aim of the study was to check the presence of privacy policy in the e government websites of Saudi Arabia regarding the use of information and the implementation of the privacy policy. 
The Paper is organized as follows. First, it will describe the background to the study. Next, it will discuss the approach undertaken in the research. Further, the results of the study have been discussed in detail. Finally, the last section will summarize the conclusion of the study.

\section{Background of the Study}

The presence of the privacy policy in any website has a broad impact on the use of the website by the user. The information practices employed by the website are defined by its privacy policy. Users all over the world are particularly concerned about the information they disclose over the internet. Users understand that they need to know the information they provide and how this information is used by the websites. The presence of privacy policy provides an assurance to the user to provide information to the website. The privacy policy of a website must also be understandable and easily accessible to the user (Annie I.Antón, Julia B. Earp \& Angela Reese, 2002). From an organization's point of view, the presence of privacy policy defines the way the business is conducted by the organization (Wouters, Simoens, Lathouwers \& Bart Preneel, 2008).

Over the past decade, data privacy laws have been introduced in a number of countries. The European Union in 1995 introduced "European privacy Directive" to ensure privacy over the internet. Privacy over the internet in United states are governed by laws like "The Children's Online Privacy Protection Act (COPPA)", " The Gramm-Leach-Bliley Act", "Health Insurance Portability and Accountability Act (HIPAA) Privacy Rules"(Elizabeth Perkins \& Mike Markel, 2004). A lot of other countries like Australia, Argentina and Canada have also introduced their own privacy laws (Perkins \& Markel, 2004; Larry Korba, 2002). Saudi Arabia in 2001 passed "The Internet Laws" to govern every aspect of information and data privacy over the internet (Saudi internet rules, 2001).

Everyday infinite amount of information is collected by the websites. Previous studies have proven that privacy concerns the users over the internet (Federal trade commission Report, 2000; Adkinson, Eisenach \& Lenard, 2002). A survey conducted by Graphics, Visualization and Usability centre of the Georgia Institute of Technology found out that $69.95 \%$ of the users were concerned providing information to the websites (James E. Pitkow \& Colleen M. Kehoe, 1997). Another study conducted by an internet privacy solution company "TRUSTe" Found that $78 \%$ of users will only disclose information if they are provided with some kind of privacy assurance. The results of these surveys established that websites that have a dedicated privacy policy page present in their websites are considered trustworthy and increase user confidence towards the disclosure of information to the website.

The regulation of the internet and the main privacy concerns are the areas that need to be thoroughly researched (James S. Wilson, 2000). As the previous studies have established that these privacy concerns can have serious consequences. Keeping the concerns of the privacy over the internet, we conducted a study on privacy policy implementation in e government websites of Saudi Arabia. The aim of this study is to measure the status of privacy policy in e government websites of Saudi Arabia.

\section{Research Methodology}

\subsection{Selecting E government Websites}

In this step, all the websites concerning the Saudi Arabian government and services were selected, and a list was created. There were a total of 54 E government websites in Saudi Arabia. A list of all E government websites is given in Table 1.

\subsection{Content Analysis}

This step was concerned with the presence of privacy page in the website. The presence of the privacy page asked for the content analysis of the privacy statement to be done. Content analysis is a research tool to derive valid inferences and concepts from the text (Earp, Antón, Aiman-Smith \& Stufflebeam, 2005). The privacy statement of each website was studied line by line to understand the level of privacy implemented by the websites. The evaluation of the privacy statement was done on the basis of the United States Federal Trade Commission's Fair Information Practice Principles (FIPs). The Fair Information Practice Principles (FIPs) are widely accepted guidelines for ensuring fair practices and is based on following core principles (Annie I.Antón et.al 2002; Richardson, Agrawal, \& Domingos, 2003).

\subsubsection{Notice/Awareness}

It should be clearly stated to the user what information is collected from him and how this information is used (Annie I. Antón et al., 2002; Richardson et al., 2003; Peter S. Gemmell, 1997). 


\subsubsection{Choice/Consent}

Users should be clearly informed about the disclosure of the information by the website (Annie I. Antón et al., 2002; Richardson et al., 2003; Peter S. Gemmell, 1997).

\subsubsection{Access/Participation}

Users must be able to access the information provided to the website (Annie I. Antón et al., 2002; Richardson et al., 2003; Peter s. Gemmell, 1997).

\subsubsection{Integrity/Security}

Websites should prevent any unauthorised access to the user data. Websites must also ensure that data remains accurate all the time (Annie I.Antón et al., 2002; Richardson et al., 2003).

\subsection{Classification}

The last part of our research methodology was classifying the websites. Once the websites were checked for presence of privacy policy, each website was classified as:

\subsubsection{Privacy policy Present}

A link to a separate page stating the privacy policy of website is present i.e. privacy policy is present.

\subsubsection{Privacy Policy Not Present}

No page or link dedicated to privacy policy of website present i.e. privacy policy not Present.

The second part of the study was to check whether the privacy policy complies to the Fair information practice principles of Notice/Awareness, choice/Consent, Access/Participation and Integrity/Security. Figure 1 demonstrates the weight age given to each of the fair Information Practice principles.

The FIP principles were given an equal weight age and based on the presence of these principles, the website's privacy policy was rated as:

1) Strong: The privacy policy of website complying with any three FIP principles was classified as Strong.

2) Weak: The privacy policy of website complying with two or less than two of the four FIP principles was classified as Weak.

\section{Results}

Considering the amount of attention that data privacy over the internet is given these days, the results of our study were shocking. It was found that out of the total e government websites in Saudi Arabia; only $28 \%$ have some kind of privacy policy present. The rest of $72 \%$ websites didn't have privacy policy present on the website. Figure 2 shows the percentage of privacy policy in e government websites of Saudi Arabia.

The results were also surprising because some of the major e government websites didn't have any privacy policy implemented.

The second part of our study was to determine the status of privacy policy based on fair information practice's principles (FIPs) of Notices, choice/consent, access /participation and integrity/security. The results about the status of the privacy policy were quite encouraging. It was found that out of the total websites where privacy policy was present, $60 \%$ has a strong status of the privacy statement while as $40 \%$ had a weak privacy statement. The status of the privacy statement is shown in Figure 3.

\section{Conclusion and Future Work}

Data Privacy and security are the major concern of organisations and users over the internet today. The most common way of implementing privacy over the internet is to ensure the presence of privacy policy in the website. Privacy policy is one of the most important documents in any website. The presence of privacy policies is important not only for users but also for the organisations as the data privacy laws differ from one place to another. The motive behind this study was to measure the presence of privacy policy in e government websites of Saudi Arabia. The results of the study showed that there are very less number of e government websites that have the $p$ of privacy policy. The less percentage of privacy policy presence in websites can be attributed to the fact that e governance is still in an emerging stage in Saudi Arabia. Another possible reason for this could be that there is not much importance given to privacy policy even in the traditional working environment of Saudi Arabia. The results showed that $72 \%$ of the e government websites don't have a privacy policy page in their websites. As far as the statuses of the privacy policy in the websites were privacy policy was present, the results were far better with $60 \%$ of strong privacy policy. The status of the privacy policy was calculated on the basis of FIP principles, which act as a benchmark for writing privacy policy for any website. 
This study was concerned only with the e government websites of Saudi Arabia. The study can be extended to other sectors as well as to other countries. Furthermore, the comparative study between sectors is highly encouraged. We recommend the study to be extended to other areas.

\section{References}

A. I. Antón \& J. B. Earp. (2000). Strategies for Developing Policies and Requirements for Secure electronic Commerce Systems. 1st Workshop on Security and Privacy in E-Commerce.

Alyson L. Young, \& Anabel Quan-Haase. (2009). Information revelation and internet privacy concerns on social network sites: a case study of facebook. Proceedings of the fourth international conference on Communities and technologies.

Annie I. Antón, Julia, B. Earp, \& Angela Reese. (2002). Analyzing Website privacy requirements using a privacy goal taxonomy. Proceedings of the IEEE Joint International Conference on Requirements Engineering (RE'02)

Efrim Boritz, Won Gyun No, \& R. P. Sundarraj. (2008). Internet Privacy: Framework, Review and Opportunities for Future Research. Proceedings of the 41st Hawaii International Conference on System Sciences. http://dx.doi.org/ 10.1109/HICSS.2008.215

Elizabeth Perkins \& Mike Markel. (2004). Multinational Data-Privacy Laws: An Introduction for IT Managers. Ieee transactions on professional communication, 47(2). http://dx.doi.org/10.1109/TPC.2004.828207

Federal trade commission. (2000). Privacy Online:Fair Information Practices In The Electronic Marketplace A Report To Congress. [Online] Available: http://www.ftc.gov/reports/privacy2000/privacy2000.pdf

James E. Pitkow, \& Colleen M. Kehoe. (1997). Federal Trade Commission Public Workshop on Consumer Information $\quad$ Privacy. [Online] Available: http://smartech.gatech.edu/xmlui/bitstream/handle/1853/3536/97-15b.pdf?sequence=1

James S. Wilson. (2000). The Use Of Survey Data In Privacy Research. A Master's paper submitted to the faculty of the School of Information and Library Science of the University of North Carolina at Chapel Hill [Online] Available: http://ils.unc.edu/MSpapers/2733.pdf

Julia B. Earp, Annie I. Antón, Lynda Aiman-Smith, \& William, H. Stufflebeam. (2005). Examining Internet Privacy Policies within The Context Of User Privacy Values. Ieee transactions on engineering management, 52(2). http://dx.doi.org/10.1109/TEM.2005.844927

Karel Wouters, Koen Simoens, Danny Lathouwers, \& Bart Preneel. (2008). Secure and Privacy-Friendly Logging for e Government Services. The Third International Conference on Availability, Reliability and Security. http://dx.doi.org/ 10.1109/ARES.2008.41

Larry Korba. (2002). Privacy in Distributed Electronic Commerce. Proceedings of the 35th Hawaii International Conference on System Sciences.

M. Richardson, R. Agrawal, \& P. Domingos. (2003). Trust management for the semantic web. In Proceedings of the Second International Semantic Web Conference.

Peter s. Gemmell. (1997). Tracable E cash. Ieee Spectrum, 34(2), 35-37. http://dx.doi.org/10.1109/6.570827

SAMIRAD. The Saudi Arabian Market Information Resource [Online] Available: http://www.saudinf.com/main/w.htm

Saudi internet rules. (2001). [Online] Available: http://www.al-bab.com/media/docs/saudi.htm

William, F. Adkinson, Jr., Jeffrey A. Eisenach, \& Thomas M. LenardA. (2002). Privacy Online: Report on the Information Practices and Policies of Commercial Web Sites. [Online] Available: http://www.pff.org/issues-pubs/books/020301 privacyonlinereport.pdf

Yesser. [Online] Available:http://www.yesser.gov.sa/en/Pages/default.aspx 
Table 1. List of E government websites in Saudi Arabia

\begin{tabular}{|c|c|}
\hline Government Department & Website \\
\hline Ministry of Communications and Information Technology & http://www.mcit.gov.sa \\
\hline Communications and Information Technology Commission & http://www.citc.gov.sa/ \\
\hline National Center for Digital Certification (NCDC): & http://www.pki.gov.sa/ \\
\hline Saudi Computer Society & http://www.computer.org.sa \\
\hline Saudi Industrial Property Authority & http://www.modon.gov.sa/ \\
\hline Saudi Post & http://www.sp.com.sa/ \\
\hline King Abdulaziz City for Science and Technology & http://www.kacst.edu.sa \\
\hline Computer Emergency Response Team-Saudi Arabia (CERT-SA) & http://www.cert.gov.sa/ \\
\hline Saudi National Anti-SPAM Program & http://www.spam.gov.sa \\
\hline Ministry of foreign affairs & http://www.mofa.gov.sa \\
\hline Ministry of Civil services & http://www.mes.gov.sa \\
\hline Saudi Arabia Government & http://www.the-saudi.net/ \\
\hline The Saudi Arabian Market Information Resource. & http://www.saudinf.com/ \\
\hline Arab Gulf Program & http://www.agfund.org \\
\hline Arab fund & http://www.arabfund.org/ \\
\hline The Ministry of Commerce and Industry (MOCI), & http://www.commerce.gov.sa \\
\hline The Council of Saudi Chambers & http://www.saudichambers.org.sa \\
\hline Eastern Province Chamber of Commerce & http://www.chamber.org.sa \\
\hline Ministry of Economy and Planning & http://www.mep.gov.sa \\
\hline Ministry of education & http://www.moe.gov.sa \\
\hline Ministry of finance & http://www.mof.gov.sa \\
\hline General Organization for Social Insurance & http://www.gosi.gov.sa \\
\hline Ministry Of hajj & http://www.hajinformation.com \\
\hline Ministry of Health & http://www.moh.gov.sa \\
\hline Ministry of Higher Education & http://www.mohe.gov.sa \\
\hline King Fahd Complex for the Printing of the Holy Qur'an & http://www.qurancomplex.org \\
\hline Ministry of Islamic Affairs, Endowments, Da'wah and Guidance & http://quran.al-islam.com \\
\hline Islamic Development Bank & http://www.isdb.org \\
\hline Jeddah Chamber of Commerce \& Industry & http://www.jcci.org.sa \\
\hline Ministry of Justice & http://www.moj.gov.sa \\
\hline King Abdul Aziz (Ibn Saud) Information Resource & http://www.ibnsaud.info/ \\
\hline King Fahd Bin Abdul Aziz & http://www.kingfahdbinabdulaziz.com \\
\hline King Faisal Foundation & http://www.kff.com/ \\
\hline King Faisal Specialist Hospital and Research Centre & http://bportal.kfshrc.edu.sa \\
\hline Ministry Of labor & http://www.mol.gov.sa \\
\hline Majlis Al-Shura & http://www.shura.gov.sa \\
\hline Ministry of Municipal and Rural Affairs & http://www.momra.gov.sa/ \\
\hline Organization of Arab Petroleum Exporting Countries (OAPEC) & http://www.oapecorg.org/ \\
\hline OPEC & http://www.opec.org \\
\hline Ministry of Petroleum and Mineral Resources & http://www.mopm.gov.sa \\
\hline Saudi Arabian Airlines & http://www.saudiairlines.com \\
\hline SAUDI ARABIA investment authority & http://www.sagia.gov.sa \\
\hline Saudi Arabian Monetary Agency & http://www.sama.gov.sa \\
\hline Saudi Aramco & http://www.saudiaramco.com \\
\hline Saudi Basic Industries Corporation & http://www.sabic.com/ \\
\hline Saudi Arabian Standards Organization & http://www.saso.org.sa \\
\hline Saudi Fund for Development & http://www.sfd.gov.sa/ \\
\hline Saudi Commission for Tourism and Antiquities & http://www.scta.gov.sa \\
\hline Saudi Geological Survey & http://www.sgs.org.sa \\
\hline Saudi Ports Authority & http://www.ports.gov.sa \\
\hline Saudi Telecommunications Company & http://www.stc.com.sa \\
\hline Saudi Press Agency & http://www.spa.gov.sa \\
\hline Ministry of Interior & http://www.moi.gov.sa \\
\hline
\end{tabular}




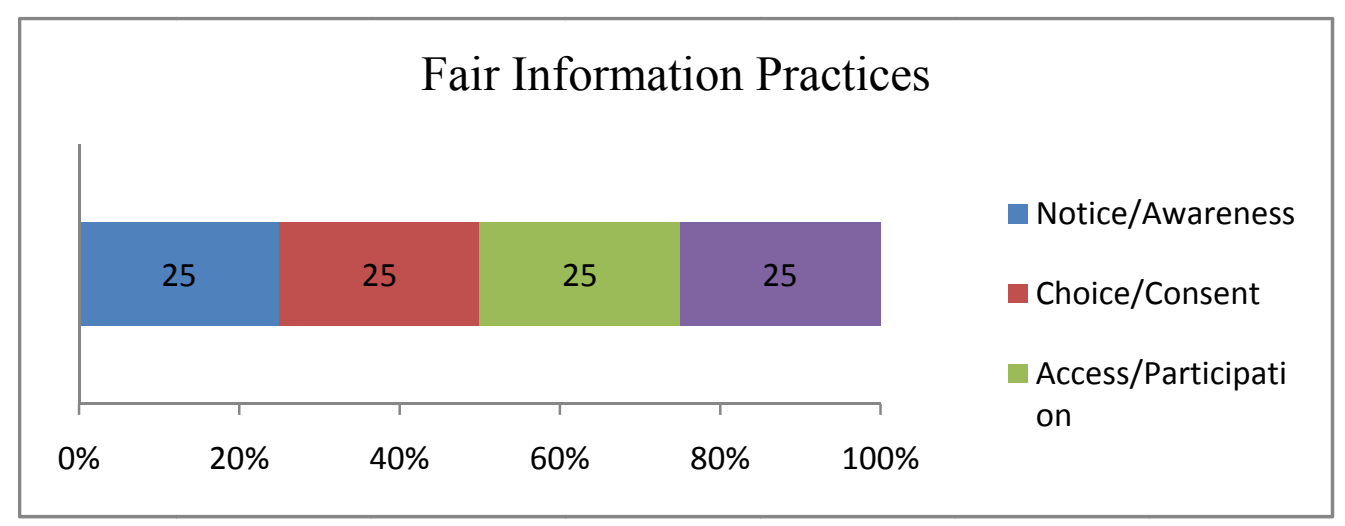

Figure 1. Fair Information Practices

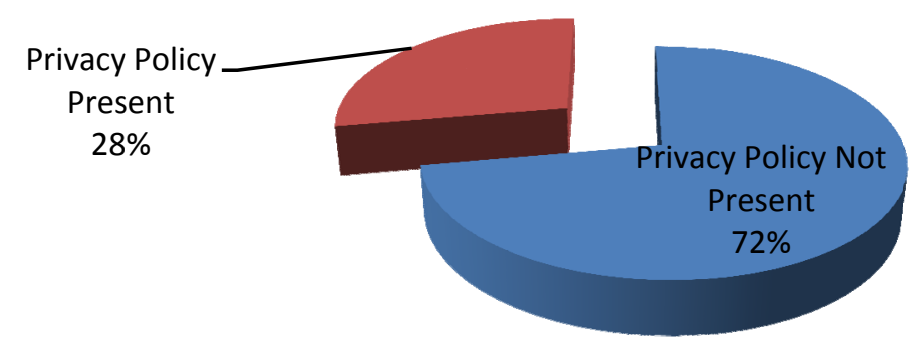

Figure 2. Privacy policy in E Government websites of Saudi Arabia

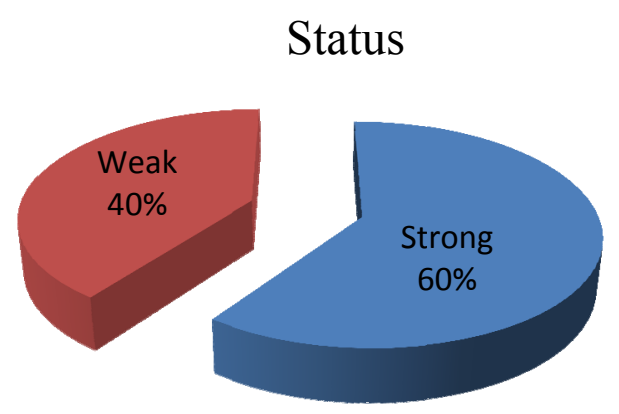

Figure 3. Status of the privacy statement 